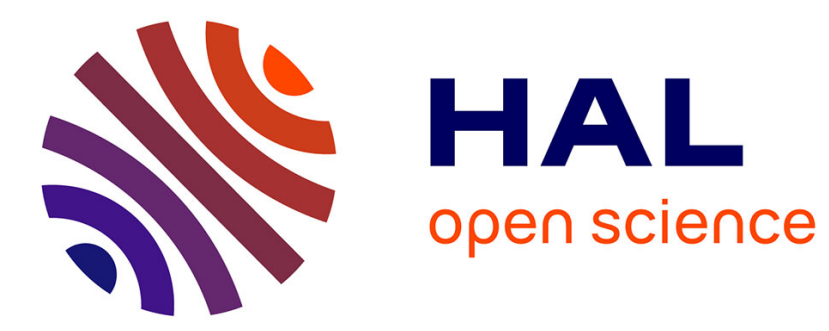

\title{
Teología moral, restitución y sociedad colonial en los Andes en el siglo XVI
}

Aliocha Maldavsky

\section{To cite this version:}

Aliocha Maldavsky. Teología moral, restitución y sociedad colonial en los Andes en el siglo XVI. Revista Portuguesa de Filosofia, 2019, 75 (2), pp.1125-1148. 10.17990/RPF/2019_75_2_1125 . hal02327458

\section{HAL Id: hal-02327458 \\ https://hal.parisnanterre.fr/hal-02327458}

Submitted on 22 Oct 2019

HAL is a multi-disciplinary open access archive for the deposit and dissemination of scientific research documents, whether they are published or not. The documents may come from teaching and research institutions in France or abroad, or from public or private research centers.
L'archive ouverte pluridisciplinaire HAL, est destinée au dépôt et à la diffusion de documents scientifiques de niveau recherche, publiés ou non, émanant des établissements d'enseignement et de recherche français ou étrangers, des laboratoires publics ou privés. 


\title{
Teología moral, restitución y sociedad colonial en los Andes en el siglo XVI
}

\author{
ALIOCHA MALDAVSKY*
}

\begin{abstract}
How to obtain eternal salvation when you are an old conquistador? Did he feel any remorse for having participated in the destructuring of entire societies and in the death of the peoples who lived in the American continent in the $15^{\text {th }}$ and $16^{\text {th }}$ centuries? Was it possible to dissolve in Catholicism the morally condemnable effects of the conquest? The restitution of goods to the Indians was one of the answers to these questions, given by theologians, jurists and rulers as early as the sixteenth century, and put into practice in the Andes by the encomenderos themselves, through donations and testaments. The objective of this article is to take restitution seriously, as a manifestation of the conscience of the old conquerors, and also to analyze the great diversity of motivations they could have to restore ill-gotten gains. This took place while the Spanish Crown was questioning their power and therefore their place in the colonial society that was then being built in the Andes.
\end{abstract}

Keywords: America, Bartolome de Las Casas, ill-gotten goods, indigenous communities, justice, moral theology, Peru, restitution, testaments.

\section{Introducción}

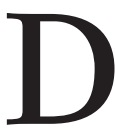

espués de la promulgación de las Leyes Nuevas en 1542 y de su relativo fracaso al concluir las guerras civiles en el Perú, religiosos y gobernantes utilizaron diversos medios para controlar el poder de los encomenderos. Muchos de ellos eran antiguos conquistadores, acusados de abusar de su poder y sospechosos de pretender fundar señoríos particulares en el territorio de sus encomiendas. Este control se ejerció mediante la teología moral, con el sacramento de penitencia, que pertenece al foro interno de la conciencia. El objetivo era exigir la restitución de los bienes mal habidos durante la conquista, en nombre 
del carácter injusto de las guerras entonces emprendidas contra los habitantes del continente americano. La restitución es una de las caras concretas de las respuestas generales y teóricas de los teólogos y juristas del siglo XVI, que se encuentran en los escritos de Francisco de Vitoria o en las Leyes Nuevas de 1542, de difícil aplicación en los Andes. Teorizada por Bartolomé de las Casas en un largo memorial publicado en 1552, ${ }^{1}$ la restitución fue aplicada y adaptada en los Andes, sin duda a raíz del papel que tuvieron los religiosos de la orden de Santo Domingo en el virreinato del Perú. Sus huellas concretas se encuentran en testamentos y donaciones redactados en los Andes en las décadas de 1550 y 1560, después de las guerras civiles y cuando los antiguos conquistadores, instalados en la nueva sociedad colonial, llegan al ocaso de sus vidas.

El objetivo de este artículo es tomar en serio la restitución, como manifestación de la conciencia de los antiguos conquistadores, y de analizar también la gran diversidad de motivaciones que pudieron tener para restituir los bienes mal habidos, en un contexto de cuestionamiento de su poder por la Corona española y por lo tanto de su lugar en la sociedad colonial que se estaba entonces conformando en los Andes. Se trata de entender no solamente la restitución como una manifestación de la mala conciencia de los colonizadores, en su calidad de cristianos, sino también de demostrar de qué manera se puede leer como un instrumento religioso de ordenamiento de la sociedad andina. Veremos que además de pertenecer al foro interno de la administración de las conciencias, la restitución forma también parte del arsenal jurídico de la Corona española en el siglo XVI para presionar a los encomenderos españoles y hacerlos respetar su deber de contribuir a la evangelización de los indios. El análisis de la documentación notarial muestra de qué manera los antiguos conquistadores enfocaron la obligación de restituir e invocaron su buena fe durante la conquista, haciendo hincapié en su estatuto de combatientes por la fe para justificar su actitud. Sin embargo, sus restituciones, al tomar la vía de obras pías caritativas, perseguían objetivos más bien relacionados con su posición en una sociedad colonial en vías de pacificación: cumplir con su deber de evangelización y reforzar su relación de poder con los indios de sus encomiendas.

1. Bartolomé de Las Casas, Aqui se contienen unos avisos y reglas para los que oyeren confessiones de los Españoles que son o han sido en cargo a los indios de las Indias del mas Océano (Sevilla: Sebastián Trujillo, 1552). Edición moderna en Bartolomé de Las Casas, Obras escogidas, t. V, Opusculos, cartas y memoriales (Madrid: Biblioteca de Autores Españoles, 1958), 235-249. 


\section{La restitución colonial: obligación, foro interno y guerra justa}

Enunciada claramente por la teología moral de Tomás de Aquino, la restitución es el deber del cristiano que se apropió un bien de manera ilegal o cometió un acto fraudulento hacia un individuo o una entidad colectiva. ${ }^{2}$ Complementa la contrición, porque traduce en hechos concretos el sentimiento de "aversión hacia el pecado cometido, con el objetivo de no cometerlo más en el futuro"; además se agrega a la confesión, que es el acto de declarar la propia contrición. ${ }^{3}$ En su calidad de acto de reparación, la restitución es la tercera etapa en el camino de la absolución, dentro del sacramento de penitencia. Es un "acto de justicia conmutativa, por el cual se devuelve al próximo un bien que le pertenecía en derecho, o por el cual se compensa el daño hecho injustamente". ${ }^{4}$ Como precio de la salvación, la restitución responde al séptimo mandamiento sobre el robo y se inserta en la práctica penitencial como una clausula habitual de los testamentos desde la época medieval. La restitución, o por lo menos la voluntad de restituir, se concibe como una necesidad, por lo tanto, sin ella la salvación es imposible. La restitución es obligatoria si la posesión del bien de otra persona se debe a una acción injusta, si esta acción es una causa eficaz, o sea que el daño fue voluntario, y si se trata de una falta teológica, o sea de un pecado mortal, con variaciones en caso de pecado venial y en caso de duda al respecto. ${ }^{5}$ Este carácter obligatorio de la reparación se revela un medio de presión sumamente potente. ${ }^{6}$ Esta definición se impuso, no sin discusiones, a partir del siglo XVI. En efecto, contra la posición de Tomas de Aquino, Jean Gerson y luego Erasmo, estimaban que la confesión era un asunto entre el penitente y Dios, que se debía respetar el secreto y que no tenía nada que ver con la justicia humana. Gerson afirmaba que la ley de los hombres no podía vincular en términos de pecado mortal y que el legislador no podía imponer penas en casos relacionados con el sacramento de penitencia. ${ }^{7}$ Esta concepción agustiniana del pecado, que

2. Francesca Cantú, "Evoluzione et significato della dottrina della restituzione in Bartolomé de Las Casas. Con il contributo di un documento inedito," Critica Storica XII-Nuova serie, no. 2-3-4 (1975), 231-319.

3. Wietse de Boer, La conquista dell'anima (Turin: Einaudi, 2004), 51. Paolo Prodi, Una historia de la justicia. De la pluralidad de fueros al dualismo moderno entre conciencia y derecho (Buenos Aires-Madrid: Katz, 2008), 69.

4. Dictionnaire de théologie catholique, 1937, s.v. "Restitution".

5. Ibid.

6. Boer, La conquista, 63.

7. Vincenzo Lavenia, L'infamia e il perdono: tributi, pene e confessione nella teologia morale 
desacredita al foro externo, fue después un argumento para la crítica de las indulgencias y se relaciona con la fiscalidad y las penas de restitución por fraude fiscal. ${ }^{8}$

En el contexto de la segunda escolástica española, la discusión sobre la distinción de los foros se relacionó con la reflexión sobre la represión de la herejía, la confiscación de los bienes y la restitución a título del fraude fiscal. Cuando Francisco de Vitoria sostiene que no se puede confiscar los bienes a los indios a título de su infidelidad, se debe al respeto de la ley natural que le reconoce su dominium a los paganos, ya sea en el sentido de la soberanía, como en el de la propiedad privada. Pero el teólogo es prudente en materia de confiscación de bienes a favor del fisco, pues teme que la conciencia del fiel se disuelva en la ley positiva, como lo proponen Juan de Medina o Alfonso de Castro. ${ }^{9}$ Castro, en particular, insiste en la «obligación de las normas humanas y en la afinidad entre la satisfacción penitencial y la pena», invitando a los confesores a "rechazar la absolución y alentar a devolver los bienes evadidos, por el medio de la cruzada". ${ }^{10}$ El canonista Martin de Azpiculeta, el Navarro (1492-1586) matiza esta posición en su manual para los penitentes, publicado en 1552 y prometido a un destino editorial excepcional. ${ }^{11}$ Azpilcueta define la restitución en términos de justicia conmutativa, pues la distingue de otras ocasiones de dar o de devolver "por amor, por caridad, misericordia, agradecimiento", que no se relacionan con la justicia y porque no se trata de la justicia distributiva, "que reparte el bien común entre particulares". ${ }^{12}$ Como lector de Erasmo y de Gerson, pone de relieve los límites de la autoridad humana, valorando el foro de la conciencia y aconsejando una actitud indulgente

della prima età moderna (Bologne: Il Mulino, 2004), 51-59. Sobre Jean Gerson, Prodi, Una historia de la justicia, 168-170.

8. Lavenia, L'infamia e il perdono, 60-61. Y Vincenzo Lavenia, 'L'Église, juge du fisc : théologie et impôt aux XVIe et XVIIe siècles,' in Philosophie de l'impôt, ed. Thomas Berns, Jean-Claude Dupont, y Mikhail Xifaras, (Bruxelles : Bruylant, 2006), 37-67. En el caso español la bula de la Cruzada cuyos fondos eran administrados por el Rey, dependen del sistema fiscal que rige a toda la Monarquía católica. José Antonio Benito, La Bula de Cruzada en Indias (Madrid: Fundación Universitaria Española, 2000).

9. Acerca del dialogo entre estas dos posiciones : Lavenia, L'infamia e il perdono, 163-182. Y Lavenia, "L'Église, juge du fisc," 46-53.

10. Lavenia, L'infamia e il perdono, 211-212.

11. Utilizamos la edición de 1566. Martin de Azpilcueta Navarro, Manual de penitentes (Estella: Adrián de Anvers, 1566). Lavenia, L'infamia e il perdono, 219-264.

12. Azpilcueta, Manual de penitentes, 185. 
por parte del confesor. Eso permite que la penitencia no sea un pretexto para la venganza y que el penitente sienta una verdadera contrición.

Bartolomé de las Casas cosecha los frutos de esas discusiones y defiende un equilibrio de los foros en materia de restitución, con el objetivo de obligar a los encomenderos a restituir, gracias a la ley del Rey. En efecto, en 1552, Las Casas formaliza el uso de la práctica penitencial como ofensiva contra los conquistadores a través de un opúsculo publicado en Sevilla cuyo fin es servir de guía a los confesores de encomenderos, preocupados por la absolución de pecadores culpables de haberse apropiado bienes de los indios fuera del derecho establecido por los teólogos de Salamanca. Por lo tanto, la restitución se transforma en el contexto de la discusión de los Justos Títulos de la Corona española en América. La confesión y la absolución de los encomenderos y de los mercaderes de armas durante las guerras de conquista están entonces subordinadas a la restitución de los bienes sustraídos a los indios, por el carácter injusto de esas guerras. ${ }^{13}$ Ya en 1536-1537, en el tratado De unico vocationis modo omnium gentium ad veram religionem, ${ }^{14}$ Las Casas concluía que la guerra era un medio injusto para llevar a los habitantes de las Indias a la religión católica: ${ }^{15}$

Todos los que hacen la mencionada guerra y todos los que con cualquiera género de cooperación, mandato, consejo, auxilio o favor, son causa de que se les declare la misma guerra a estos fieles, cometen pecado mortal, y gravísimo por cierto. ${ }^{16}$

Las Casas se sitúa en la línea establecida por Francisco de Vitoria quien, en su Relectio de Indis, considera que, en virtud del derecho natural, común a todos los hombres, los indios poseen el dominium sobre sus vasallos como sus bienes. La teoría de la guerra justa, defendida por Vitoria y la escuela de Salamanca, concluye que la conquista no podía ser justificada por la infidelidad o el paganismo de los indios, ni porque habrían desobedecido a la ley natural. Las bulas pontificias de finales del siglo XV y del principio del siglo XVI no justifican tampoco el dominium porque el hecho de que los papas posean la autoridad temporal es discutible y

13. Las Casas, Aqui se contienen unos avisos.

14. Bartolomé de Las Casas, Del único modo de atraer a todos los pueblos a la verdadera religión, ed. Lewis Hanke (México: Fondo de cultura económica, 1975 [1942]), 422-476.

15. Cantú, "Evoluzione et significato", 247-251.

16. Las Casas, Del único modo, 434-435 
no tiene fundamento sólido. ${ }^{17}$ Para Vitoria, ni el canibalismo, ni el sacrificio humano, ni la idolatría son pecados suficientes para privar a alguien de su dominium. También refuta la idea de que los indios son esclavos naturales. El dominium de los reyes de Castilla se justifica entonces con el jus gentium, el derecho de gentes, que garantiza a los españoles la libertad de circular, el derecho a comerciar y a predicar el cristianismo. La obstrucción al jus gentium justifica una guerra justa y la apropiación por el vencedor del dominium del vencido. ${ }^{18}$ Por lo tanto, para Las Casas la mayoría de las guerras en las que los conquistadores participaron son injustas y los bienes tomados a los indios mal habidos.

Los Avisos publicados por Las Casas en 1552 son una verdadera guía para la redacción de los testamentos, pues exigen que el encomendero designe delante de un escribano a su confesor, encargado de las restituciones. También tiene que explicar en su testamento en qué guerras contra los indios y en qué conquistas participó, además de declarar si todo lo que posee viene de los indios y de prometer no revocar el testamento. ${ }^{19}$ Esta exigencia se verifica en una serie de textos redactados por los religiosos en el Perú, también dedicados a guiar a los confesores de españoles y a influenciar, a través de las conciencias, el tratamiento de los indios. Estos textos retoman los argumentos de Las Casas, adaptándolos al contexto andino. Los más importantes son el Parecer de D. Fr. Tomas de San Martin, obispo de Charcas, sobre si son bien ganados los bienes adquiridos por los conquistadores, pobladores y encomenderos de las Indias, probablemente de los años $1550,{ }^{20} \mathrm{y}$ los Avisos breves para todos los

17. Rolena Adorno, Polemics of Possession in Spanish American Narrative (New Haven: Yale University Press, 2007), 73-74.

18. Lavenia, L'infamia e il perdono, 156-162 y Anthony Pagden, "Dispossessing the barbarian: the language of Spanish Thomism and the debate over the property rights of the American Indians," in The languages of political theory in early modern Europe, ed. Anthony Pagden (Cambridge: Cambridge University Press, 1987), 79-98. Anthony Pagden, "The school of Salamanca and the 'Ius Naturae', "The uncertainties of empire: essays in Iberian and Ibero-American intellectual history (Aldershot: Variorum, 1994). Sobre Las Casas y la guerra justa, Lewis Hanke, La Lucha por la justicia en la conquista de América (Buenos Aires: Ed. Sudamericana, 1949), 249-278.

19. Dos artículos fundadores estudian la cuestion de la restitucion en el Perú, como manifestacion de la influencia de Las Casas y de los dominicos: Guillermo Lohmann Villena, "La restitución por conquistadores y encomenderos: un aspecto de la incidencia lascasiana en el Perú," Anuario de Estudios americanos 23 (1966), 21-89; Guillermo Lohmann Villena, "El encomendero indiano, cooperador de la evangelización," in Homenaje al profesor Alfonso García Gallo, vol. 5 (Madrid: Universidad Complutense, 1996), 113-136.

20. Tomás de San Martin, "Parecer de D. Fr. Tomas de San Martin, obispo de Charcas, 
confesores destos Reynos del Perú (Instrucciones), firmado en 1560 por un ajunta de prelados presidida por Jerónimo de Loaysa, dominico y primer arzobispo de Lima. ${ }^{21}$

\section{Justicia real y restitución: deber de evangelización y fiscalidad}

Si los religiosos se rigen por los principios de los Justos títulos, la ley divina y el foro de la conciencia, la ley del Rey no guarda silencio sobre la restitución. La Recopilacion de 1681 repite una cédula real dirigida a la audiencia de Lima, del 10 de mayo de 1554 que recuerda que el objetivo de las encomiendas es la conversión de los indios y su instrucción en la fe católica. Si los encomenderos no respetan ese deber, "sean obligados a restituir los frutos, que han percevido, y perciven, y es legitima causa para privarlos de las encomiendas". El Rey le pide a los "Virreyes, Audiencias, y Governadores, que con mucho ciudado, y diligencia inquieran, y sepan por todos los medios posibles si los Encomenderos cumplen con esta obligación: y si hallaren, que faltan a ella, procedan por todo rigor de derecho a privarlos de las encomiendas, y hazerles restituir las rentas, y demoras, que huvieren llevado, y llevaren sin atender a lo que son obligados, las quales proveeran, que se gasten en la conversión de los Indios". ${ }^{22}$ Otra ley sintetiza unas cédulas de Carlos V del 20 de noviembre de 1536 y del 9 de mayo de 1551:

Los Encomenderos negligentes, y descuidados en poner la devida, y necesaria diligencia, y cumplir su obligacion, no procurando, ni teniendo Ministros para la doctrina, y administracion de los Sacramentos a los Indios de sus encomiendas, y que no han proveido suficientemente sus Iglesias, y ornamentos al culto divino necesarios, ni han satisfecho a los

sobre si son bien ganados los bienes adquiridos por los conquistadores, pobladores y encomenderos de las Indias," in Colección de documentos inéditos relativos al descubrimiento, conquista y organización de las antiguas posesiones españolas de América y Oceanía, vol. 7 (Madrid: Frias y Cia., 1867), 348-362. Archivo General de Indias, Patronato 252, ramo 21.

21. Antonine Tibesar, "Instructions for the Confessors of Conquistadores Issued by the Archbishop of Lima in 1560," The Americas 3, no. 4 (Apr. 1947): 514-534.

22. Recopilación de las leyes de Indias (Madrid: Julián de Paredes, 1681), Libro VI, Título IX, Ley I, f. 229 y Ley III. Richard Konetzke, Colección de documentos ara la Historia de la Formación social de Hispanoamérica, 1493-1810, T.I. (Madrid, 1953), 322-325. María de las Mercedes del Río, Etnicidad, territorialidad y colonialismo en los Andes: tradición y cambio entre los Soras de los siglos XVI y XVII, Bolivia (Lima: Instituto Francés de Estudios Andinos, 2005), 226-227. 
Ministros trabajo, según lo expressado en las leyes de este libro, declaramos, que demás de haver estado, y estar, en culpa muy grave, son obligados a restituir todo aquello, que justamente se deviera gastar en lo susodicho. $^{23}$

En la década de 1550, la restitución refuerza este conjunto legislativo cuyo objetivo es limitar el poder de los encomenderos, regular la percepción del tributo y el uso del trabajo nativo. ${ }^{24} \mathrm{El}$ Rey no les pide a los encomenderos que restituyan los bienes mal habidos por su participación a guerras injustas y no toma en cuenta la cuestión de los justos títulos ni de la conquista, que sin embargo eran centrales para Las Casas en 1552. Si al derecho positivo le interesa la conciencia de los encomenderos, es para reprocharles de no haber respetado su deber para con el Rey, asimilando esta falta a un pecado. Esta afirmación era discutible para los teólogos cuando debatían sobre la fiscalidad y la legalidad del impuesto real. ${ }^{25}$ Pero esos detalles no son tan importantes para los religiosos, cuya prioridad es influir en la conciencia de los españoles en América. Por lo tanto, la legislación de los Habsburgo se concentra, en la década de 1550, en los excesos de los encomenderos respecto del tributo y del deber de evangelización de los indios.

Mientras que el texto de Las Casas no se concentra en la cuestión del tributo, a pesar de insistir en la importancia de la justicia real, las Instrucciones del arzobispo Loayza conectan el tributo con la falta de doctrina cristiana, pues parte del tributo debe servir a financiar la presencia de un cura que les enseñe el catecismo a los indios y administre los sacramentos. La "doctrina suficiente" se define así:

Que ningun niño muera sin bautismo ni ningun adulto baptizado sin confision y que todos sepan las cossa necesarias a la fe como el credo pater noster ave maria y los diez mandamientos de la ley y los mandamientos de la iglesia y se le platique y de a entender lo susodicho en la mejor manera que ser pudiere según su capacidad. ${ }^{26}$

23. Recopilación de las leyes de Indias, Libro VI, Titulo IX, Ley III, f. 229v.

24. Silvio Zavala, La encomienda indiana (Madrid: Junta para ampliación de estudios e investigaciones científicas-Centro de estudios históricos, 1935), 114-138 y sobre los Andes: 174-177. Silvio Zavala, El servicio personal de los indios en el Perú, 3 vol. (México: El Colegio de México, 1978).

25. Lavenia, "L’Église, juge du fisc", 37-67.

26. Tibesar, "Instructions", 529-530. 
Los prelados reunidos en 1560 deciden que los encomenderos deberán restituir el tributo pagado por los indios que no sirvió a pagar a un instructor laico o a un cura. Esta restitución se debe calcular en función del tiempo que los indios pasaron sin instrucción religiosa. ${ }^{27}$ Además, los confesores tienen que verificar que los encomenderos se preocuparon personalmente de que curas y religiosos respetaran sus deberes correctamente. Por fin, los encomenderos tienen que averiguar que los indios pueden, sin prejuicio para sí mismos, pagar los tributos evaluados en las tasas. ${ }^{28}$

Este grado de precisión andino sobre la instrucción religiosa y los excesos en la percepción del tributo se explican por el contexto político delicado en el que se encuentran los encomenderos después de la rebelión de Gonzalo Pizarro y en pleno debate sobre la perpetuidad de las encomiendas, que sigue hasta finales del siglo XVI. Después de la victoria del bando real en Jaquijahuana en abril 1548, con el licenciado La Gasca se pone fin política y militarmente ${ }^{29}$ a la rebelión contra las Leyes nuevas. Los religiosos dominicos participan en el ordenamiento administrativo al que se procede entonces, a través de la visita general de las encomiendas. Su fin es evaluar definitivamente el tributo que los indios le deben al Rey y a los encomenderos, una vez que La Gasca procede a un nuevo repartimiento de encomiendas en Guaynarima, para recompensar a los encomenderos que combatieron contra Pizarro. El repartimiento y la visita son los elementos claves de una negociación entre las autoridades y los encomenderos, en los que participaron los tres religiosos dominicos, Jerónimo de Loaysa, Tomás de San Martin y Domingo de Santo Tomás. Estos religiosos fueron visitadores y procedieron a la evaluación del tributo en Lima, con los documentos de la visita efectuada entre agosto de 1549 y 1553, en su última fase. ${ }^{30}$ Esta visita fue lo que inspiró a Domingo de Santo Tomás,

27. "Yten se determino que el que falto de tener doctrina todo el tiempo que no la tuvo por ningun ministro ni por su persona lo que avia al padre sacerdote o sacerdotes necesarios para el enseñamiento bastante de los yndios a de rrestituir a los yndios según el tienpo que no tuvo la dicha doctrina", Tibesar, "Instructions", 530.

28. Tibesar, "Instructions", 530-531.

29. Gregorio Salinero, La trahison de Cortés: désobéissance, procès politiques et gouvernement des Indes de Castilles, seconde moitié du XVIe siècle (Paris : Presses universitaires de France, 2014).

30. Un análisis sintético de esta participación en Teodoro Hampe Martínez, "Fray Domingo de Santo Tomás y la encomienda de indios en el Perú (1540-1570)," in Los dominicos en el Nuevo mundo, ed. José Barrado (Salamanca: San Esteban, 1990), 354379. Un analisis más fino de la visita y de la política del compromiso de La Gasca en 
prior del convento dominico de Lima, su carta al rey del $1^{\circ}$ de julio de 1550 , en la que expone detalladamente el tratamiento inhumano infligido por los españoles a los indios. Invita al Rey a restituir para reparar los agravios cometidos y aliviar su conciencia: "Si vuestra alteza manda se prouea limosna para ello, o, por mejor dezir, se les Restituya algo de lo que les tomamos, será obra que, allende de permanescer, será de gran servicio de nuestro señor y descargo de su Real consciencia". ${ }^{31}$

El objetivo de la evaluación del tributo, que además plantea el problema del consentimiento al pago de contribuciones por los indios, era permitir que los encomenderos y el Rey pudieran cobrar los tributos sin daño para su conciencia. Por eso el texto de Tomás de San Martin se concentra también en el tributo y pide que se evalúen los pagos excesivos efectuados sin una tasación por parte de la autoridad real, considerada como la principal instancia reguladora. ${ }^{32}$ El dominico enumera gran cantidad de abusos por los encomenderos, sin duda observados durante su participación a las visitas de evaluación del tributo en las que participó. Según Tomás de san Martin, el encomendero tiene que restituir si les pidió a los indios artículos diferentes de los que enumera la evaluación, si pidió alimentos, si hizo trabajar a los indios en sitios cuyo clima era muy diferente al que éstos estaban acostumbrados, y sobre todo las minas, si no les pagó su trabajo y su desplazamiento, si quemó casas de los indios, si les tomó animales de carga sin pagar. Son los mismos abusos que Domingo de Santo Tomás enumera también en sus cartas.

La evaluación del tributo en los Andes se repite varias veces, en relación con la caída demográfica de la población y las dificultades de la economía local para responder a la presión fiscal. Las "retasas" se producen rápidamente, lo que causa la rebelión de Francisco Hernández Girón, entre noviembre de 1553 y octubre de 1554, último ejemplo de la oposición violenta de los encomenderos a las Leyes Nuevas y a la política de la Corona. ${ }^{33}$ En la década de 1560 , se producen nuevas evaluaciones, durante el virreinato de Andrés Hurtado de Mendoza, marqués del Cañete

Carlos Sempat Assadourian, "La renta de la encomienda en la década de 1550 : piedad cristiana y deconstrucción," Revista de Indias, vol. XLVIII, no. 182-183 (1988),109-146.

31. Emilio Lisson Chaves, La Iglesia de España en el Perú I-4 (Sevilla: Editorial católica española, 1944), 190-207.

32. San Martin, "Parecer", 351-352.

33. Salinero, La trahison, 179-197. 
(1556-1560). ${ }^{34}$ Al tributo se agrega el problema del trabajo indígena, servicio personal, que se termina prohibiendo. ${ }^{35}$

Las evaluaciones del tributo desde 1549 en adelante, la discusión sobre la perpetuidad de las encomiendas a la que participan los dominicos, la publicación de los Avisos de Las Casas y la reflexión sobre la restitución de bienes por conquistadores y encomenderos en la década siguiente, coinciden con una legislación que insiste en el respeto del compromiso religioso que conlleva la encomienda, como gracia real. Entonces, la cuestión de los justos títulos se desdibuja dando mayor visibilidad a la de los abusos relacionados con el tributo y el trato de los indios. La ofensiva contra los encomenderos se refiere entonces a las leyes divinas y a las humanas, al foro de la conciencia y al foro externo, al pecado y al delito. En los Andes, los religiosos optan por el partido de los teólogos que opinan, acerca de la legitimidad de los impuestos, que se puede recurrir a la ley divina para castigar delitos fiscales. Evadir la porción del tributo que se debe utilizar para pagarle a un cura se considera claramente como una evasión fiscal. Por lo tanto, si los religiosos de los Andes se remiten a la definición de Vitoria de la guerra justa, no adoptan su posición sobre la fiscalidad y su contestación del "uso de la excomunión para obligar a los fieles a restituir el dinero y los bienes evadidos al fisco" ${ }^{36}$ Esta complementariedad de los foros se verifica en las encuestas pedidas por La Gasca antes de volver a España en 1550 acerca del respeto por los encomenderos de la evaluación del tributo y se manifiesta concretamente en algunos juicios por falta de doctrina y por cometer excesos en la percepción y malos tratos. ${ }^{37}$

En la década de 1550, la justicia real se apodera de la restitución y ésta se trasforma en arma política. La cuestión de los justos títulos ya no es fundamental y deja el paso a una política de la casuística, en la que los juicios de los que se conserva el rastro le competen a una economía de la gracia real, en la que la restitución se vuelve un "medio para imponer la obediencia". ${ }^{38} \mathrm{Si}$ de la teología moral se pasa a la ley del Rey, la porosidad

34. Sempat Assadourian, "La renta de la encomienda", 128.

35. Zavala, El servicio personal de los indios en el Perú.

36. Lavenia, "L’Église, juge du fisc", 50.

37. Existen una docena de casos en la región de Charcas. Thomas Abercrombie, "Tributes to Bad Conscience: Charity, Restitution, and Inheritance in Cacique and Encomendero Testaments of 16th-Century Charcas," in Dead Giveaways, Indigenous Testaments of Colonial Mesoamerica end the Andes, ed. Susan Kellogg y Matthew Restall (Salt Lake city: University of Utah Press, 1998), 249-289.

38. Lavenia, "L’Église, juge du fisc", 49. 
entre los foros se verifica también en los discursos de los mismos conquistadores a la hora de restituir.

\section{Restitución, culpa y buena fe de los conquistadores}

El negar la absolución por parte de los confesores tuvo un impacto real en la sociedad peruana. Desde la década de 1550, cuando los poderes de los encomenderos son cuestionados por la Corona, en particular por la discusión sobre la perpetuidad de las encomiendas, y a raíz de los escritos de Las Casas y las Leyes nuevas, aparecen en los testamentos de los encomenderos cláusulas de restitución de bienes a los indios.

Para verificar la aplicación de las instrucciones en el Perú, hemos compilado unos 80 documentos, redactados entre 1536 y 1600, en diferentes sitios del virreinato peruano. Se trata sobre todo de testamentos, pero también de donaciones, de poderes para testar y de codicilos, que contienen las voluntades de 76 encomenderos y encomenderas. El examen de estos documentos revela que hasta 1549, solamente tres individuos (de los 23 documentos encontrados para esas fechas, que se refieren a 22 personas) aluden a la conversión de los indios dejando dinero para misas a favor de la evangelización (María Martel, $1547^{39}$ ), o dinero para financiar un cura de doctrina (Gómez de León y Rodrigo de Mazuelas, 1548 ${ }^{40}$ ). Las cláusulas de restitución y de donación a los indios "para descargar la conciencia" aparecen en los documentos a partir de la década de 1549, y hasta 1569. Para esas fechas se destacan 28 documentos firmados por 26 personas, donde aparecen cláusulas de restitución o de donación a los indios del Perú, conformes a la definición canónica y adaptadas al contexto americano.

Las adaptaciones más significativas tienen que ver con la obligación de restituir, la buena o la mala fe respecto de la detención del bien ajeno, el carácter solidario, la definición del o de los destinatarios y las modalidades de la restitución. El derecho distingue entre el que posee en buena fe el bien ajeno y el ladrón o el estafador, que se considera de mala fe. El que posee un bien de buena fe no sabe que su posesión se debe a un acto injusto. Salvo si se prescribe el delito, su buena fe se termina cuando se

39. Archivo general de la nación del Perú (AGNP), Protocolos, siglo XVI, Pedro de Salinas, $\mathrm{n}^{\circ} 154$ (2), f. 477-483.

40. Lohmann Villena, "La restitución por conquistadores," Antonio de Egaña, Monumenta Peruana 3 (Roma: Institutum Historicum Societatis Iesu 1954)147-162. 
entera del carácter injusto de su posesión, porque "res clamat domino" (el bien pide su propietario). ${ }^{41}$ Por lo tanto, tiene que restituir el bien. El que posee de mala fe es consciente del carácter ilegitimo de su posesión. ${ }^{42}$ Este argumento de la buena fe había sido utilizado por los teólogos de Salamanca para disculpar a los Reyes católicos, que habían creído de buena fe poseer la soberanía sobre América, porque ignoraban que las bulas pontificales no eran válidas. En los Andes, la buena fe interviene explícitamente en la redacción de algunos testamentos de encomenderos que restituyen.

Nicolás de Ribera el Viejo, primer alcalde de Lima, declara en una donación del 13 de mayo de 1556, con la cual restituye bienes a los indios: "Entendi con buena fee, creyendo ser permitidos por la dha. conquista, e que justa y licitamente se podia hacer guerra a los naturales deste Reyno por ser ynfieles, ansi para que dexassen la gentilidad en que vivian e se les predicasse el sagrado Euangelio de $\mathrm{N}^{\circ}$ Redemptor Iesuxpo. e fuessen enseñados en nra, sancta fee catholica, como por hauer Su Magestad dado facultad y licencia al dho. Marqués p.a hacer la dha. conquista e predicaciôn del dho. Euangelio, segund a Su Magestad le fue cometido e encomendado por nro. muy sancto Padre el Sumo Pontifice de la sactan Yglesia de Roma". 43

El 20 de noviembre de 1565, Lucas Martiez Vegazo, encomendero de Tarapacá, residente en Arequipa, pero de paso por Lima, desarrolla el mismo argumento en un testamento con el cual restituye bienes a los indios de su encomienda. En el preámbulo que resume las conquistas en las que participó declara:

Juro y declaro que desde prinzipio que entré en esta tierra hasta que todo se acabó de ganar, andube siempre con buena fe, paresciendome que la guerra que se hazía a los naturales della er ajusta porque la hazía gobernador cristiano y enviado por rey cristiano, como si se hiziera contra infieles turcos o moros; y no dudé en esto ni oy (sic) decir a hombre lego, no sacerdote en púlpito o fuera del, ni tal cosa se trató entre nosotros que yo supiese ni a mi noticia viniese, y si yo supiera que la guerra era injusta y lo que en la tierra se avía era mal avido, y obligado a restituir lo buscara remedio por otra vía y no viniese a Pirú, ni entrara en la conquista del; y pues tuve buena fe y Dios sabe si en esto digo verdad, y ni teólogo ni

41. Dictionnaire de théologie catholique.

42. Dictionnaire de théologie catholique.

43. José de la Riva-Agüero, El primer alcalde de Lima, Nicolas de Ribera el viejo y su posteridad (Lima: Librería e imprenta Gil, s. a.,1935), 28-29. 
hombre humano puede saber otra cosa de mi yntenzión porque no lo ubo, suplico a su divina Magestad que tenga esta buena fe que digo que tuve por tal que con ella e de morir y descargarme ante (él) el día del juizio. ${ }^{44}$

El argumento de Nicolas de Ribera el Viejo y de Lucas Martinez Vegazo revela no solamente que estos conquistadores entienden las sutilezas de la teología moral que define la restitución, sino también una verdadera resistencia a la presión de los religiosos, a pesar de que se someten. Sus argumentos resaltan la convicción de que su lugar en la sociedad se justifica por su papel de soldados. Concretamente muchos de estos encomenderos son padres de familia y/o administradores, celosos por hacer fructificar sus bienes y dejar ya sea un linaje, ya sea por lo menos un rastro de su paso por la vida. Después de las guerras civiles y con el desarrollo de una economía fundada en el trabajo y el tributo de los indios, los encomenderos experimentan un periodo de paz, de vida urbana sedentaria y de logro económico esperanzador para el futuro. La perspectiva de fundar un linaje, asentado en la posesión de una encomienda y la memoria de sus hazañas militares, explica que los encomenderos luchen en las décadas de 1550 y 1560 por evitar la extinción de la institución. Esta lucha coincide con un cambio de generación de los españoles de los Andes, con el nacimiento y la madurez de los criollos nacidos en América, que heredan de sus padres y esperan sacar provecho de su posición social. También coincide con la necesidad, para esa primera generación de españoles anclados en el Nuevo Mundo, de velar por la salvación de su alma, de sus bienes y de su posteridad. Eso explica el recurso a los documentos notariales, donde dejan por escrito, bajo la mirada de los clérigos y de los escribanos, sus esperanzas escatológicas y sus propias interpretaciones de la restitución.

$\mathrm{El}$ argumento de la buena fe que usan los encomenderos tiene que ver con la convicción de ser los defensores de la fe católica frente a los indios asimilados a los moros o a los turcos. No se trata de lamentar, sino más bien de reproducir una representación del mundo colonial basada en categorías religiosas que los teólogos y los juristas no pueden modificar y que remiten a la ideología de la Reconquista, cuya función es fundadora del universo de los conquistadores. Sin embargo, las restituciones se

44. Efraín Trelles Aréstegui, Lucas Martínez Vegazo: funcionamiento de una encomienda peruana inicial (Lima: Fondo editorial de la Pontificia universidad católica del Perú, 1991), 286-287. 
producen a pesar de las reticencias y de las afirmaciones de buena fe de los españoles.

\section{Restitución, caridad y obra pía: una relación de poder}

La reflexión teológica sobre las circunstancias de la restitución define también la regla de la restitución solidaria. Esto significa que cada cual deber restituir en nombre de todos los que cometieron el robo, si éste fue en reunión. "La obligación in solidum, que se deduce de la acción solidaria, consiste en que cada uno de los cómplices está obligado a una reparación total, por lo tanto el pago de uno libera a los otros; sin embargo éste, para compensar, tiene derecho a recurrir contra los otros, teniendo en cuenta la jerarquía de la solidaridad". ${ }^{45}$ Esta solidaridad no consta en las restituciones de los encomenderos de los Andes, cuyas modalidades más bien afirman la piedad y la devoción personal.

Los canonistas prevén que, si se conoce al verdadero propietario, se le debe restituir a él o a sus herederos. Si no se le conoce, la restitución toma la forma de un acto de caridad hacia los pobres o de una obra pía. ${ }^{46}$ La restitución se puede diferir, e incluso obviar, en diversos casos, como el de la miseria del poseedor, ${ }^{47}$ si se teme que el bien restituido sirva para cometer un pecado o para dañar a otros, o si el poseedor es incapaz, moral o físicamente, de proceder a la restitución. El derecho prevé que la autoridad superior dispense al poseedor de restituir en caso de obra pía. ${ }^{48}$ Azpilcueta escribe:

También quando no se sabe (hechas las diuidas diligencias) quien es señor de lo que se ha de restituyr, o esta tan lexos, o en tal lugar que no se le puede embiar, o no sin gran peligro o escandalo, entonces deuese restituyr a Iesu Christo, señor y heredero universal, como lo diximos alibi, dándolo a sus pobres, o a otras obras pias. ${ }^{49}$

Todas esas precisiones intervienen directamente en los casos de restitución por parte de los antiguos conquistadores y encomenderos en América, porque la catástrofe demográfica que diezma a la población

45. Dictionnaire de théologie catholique, coll. 2488.

46. Dictionnaire de théologie catholique, coll. 2489-2494.

47. Azpilcueta, Manual de penitentes, 205-206.

48. Dictionnaire de théologie catholique, coll. 2495-2499.

49. Azpilcueta, Manual de penitentes, 194. 
indígena en el siglo XVI también hace desaparecer a las víctimas de los robos. Además, los españoles que poseen bienes de forma ilegítima pueden haber vuelto a Europa o ser incapaces de restituir por encontrarse en serias dificultades financieras. Las cláusulas de restitución que vemos en los documentos son muy diversas: se restituyen directamente dinero o rentas, también algunos exentan a los indios del tributo, se pagan misas por la conversión de los indios a título de restitución, se dona dinero a hospitales de indios en pueblos y ciudades, se dan prendas de vestir a los indios pobres de la encomienda, se financia el culto por un tiempo, se financian campanas, se dona ganado e incluso existe un legado universal a los indios. Algunos arruinan a su familia, como Francisco de Fuentes en $1560,{ }^{50}$ otros limitan sus donaciones o dejan la gestión del dinero en manos de religiosos, con cláusulas que precisan sus últimas voluntades.

El 13 de mayo de 1556, en el marco de la fundación del hospital de indios de Ica, donde está su encomienda, Nicolás de Ribera el Viejo declara que desea lavar sus pecados hacia los indios

a causa de no haber enteramente guardado la orden que para justificación de la dicha conquista era necesaria, y por haber cometido algunos excesos, así en el maltratar a dichos indios como en haberles tomado algunas cosas indebidamente, o haber cobrado o recebido de ellos algunos tributos demasiados y fuera de los que honesta y buenamente, sin mucho trabajo ni fatiga de sus personas, me podían y debían tributar, o por haber yo dexado de cumplir con ellos lo que en recompensa de dichos tributos y servicios soy obligado, o por no les haber dado tan bastante y cumplida doctrina como debía, o por otras causa y cosas hechas sobre la conquista, podía y puedo haber incurrido en algunos cargos de conciencia, y sería posible que esté obligado a restituir el daño, y tengo voluntad de salir del cargo y satisfasser a todos y qualquier indios a quien esté obligado, para satisfazion y enmienda de lo susodicho, y por via de restitucíon, como más convenga a la seguridad y saneamiento de mi anima. ${ }^{51}$

La conquista, la falta de doctrina cristiana y la percepción indebida de tributos son los principales motivos de restitución, que aparecen en las recomendaciones de los religiosos, ya difundidas en 1550, cuando aún el tratado de Las Casas no había sido publicado. El 4 de enero de 1563, tres años después de las Instrucciones de Loayza, Nicolás de Ribera el Viejo

50. Lohmann Villena, "La restitución por conquistadores", 29-30.

51. Riva-Agüero, El primer alcalde de Lima, 29. 
vuelve a examinar su restitución, con un último codicilo que revoca a sus anteriores albaceas, para nombrar, entre otros, a su esposa, doña Elvira Dávalos, considerada como una benefactora de los religiosos de Santo Domingo de Lima, y a Fray Domingo de Santo Tomás, apenas elevado a la dignidad de obispo de Charcas por Jerónimo de Loayza, en 26 de diciembre de $1562 .{ }^{52}$ Ribera explica que les deba a los indios una cifra global de 14000 pesos, de los cuales

6000 pesos confieso que los devo bien debidos a los yndios deste rreino en general de cosas que les he llevado y me e aprovechado dellos. Item declaro que demás de lo que hasta oy e pagado y dado y soltado a los yndios de Hica de mi encomienda e hecho y averiguado quenta de mi conciencia y consultado con theologos y letrados de letras y conciencia que dello tienen expiriencia y confieso que les devo y soi a cargo 8000 pesos de oro y plata ensayada y marcada, mando que se les paguen de mis bienes. ${ }^{53}$

Las modalidades de la restitución respetan las recomendaciones de los religiosos, pues a los "indios deste rreino", que no se pueden identificar precisamente, Nicolás de Ribera deja unos censos sobre las casas que posee, cuyo valor tendrá que ser dividido entre tres hospitales, un tercio para el hospital de los indios de Lima, un tercio para el del Cuzco y el último tercio para el de Ica, que él mismo contribuyó a fundar, bajo el patrocinio de san Nicolás, su propio santo patrón. El valor de dichas casas es de 7000 pesos y los indios de Ica tienen derecho a un censo situado en 1000 pesos más. Ribera calcula que le debe restituir 7000 pesos más a los indios de Ica y pide que cuatro años después de su muerte, se les pague, durante cuatro años, 1000 pesos cada año, que sirvan a comprar posesiones o censos. Los 3000 pesos que le quedan por pagar a los indios de Ica, pide que se les den en ganado u otra cosa, tres años después de su muerte, para distribuirlos entre los indios de la comunidad. Los censos adquiridos tendrán que ser administrados por el patrón del hospital indios de Ica, cuya identidad no aparece en el texto. ${ }^{54}$

52. Riva-Agüero, El primer alcalde de Lima, 33. Teodoro Hampe Martinez, Fray Domingo de Santo Tomás y la encomienda en el Perú (1540-1570) », Los dominicos en el Nuevo mundo (Salamanca: San Esteban, 1990), 355-379, 375.

53. Ruben Vargas Ugarte, "Archivo de la beneficencia del Cuzco," Revista del Archivo Histórico del Cuzco, no. 4 (1953), 105-106.

54. Vargas Ugarte, "Archivo de la beneficencia del Cuzco", 106-107. 
El texto toma en cuenta la justicia real. Nicolás de Ribera el Viejo agrega que ruega y pide

por merced a las justicias de Su Magestad que por todo rigor de derecho o via executiva me compelan a mi y a los dichos mis herederos y albaceas a cumplir e pagar lo susodicho, según y de la forma que está dicho e declarado, bien ansy como si lo que dicho es y fuere sentencia definitiva de juez competente, por mí consentida e pasada en cossa juzgada, en razón de lo qual rrenuncio qualesquiera leyes, fueros y derechos y hordenamientos que en mi fabbor e de los dichos mis herederos sean o ser puedan. ${ }^{55}$

No es de dudar que Fray Domingo de Santo Tomás participó activamente en la redacción de este codicilo. El obispo de Charcas, cuyo espíritu lascasiano es conocido, ${ }^{56}$ respeta el procedimiento previsto en las Instrucciones de Loayza de 1560: la necesidad de evaluar los bienes robados, la distinción entre los indios que no se pueden identificar y a los que Ribera debe en general, porque se perdió su huella o porque el conquistador no sabe quiénes son, y los indios identificados, que son los de su encomienda de Ica, a quien restituye directamente parte de sus bienes. A los primeros, les restituye a través de una fundación piadosa, un hospital, cuya gestión se encomienda en general a religiosos. A los indios de Ica les restituye según modalidades precisas, para evitar pérdidas de dinero. El plazo que define para la restitución, en bienes como ganado y no en dinero, y la compra de censos, en vez de una restitución directa, cobran también sentido cuando se analizan en términos de relación de poder.

El ejemplo de una restitución en ganado nos lo brinda el caso de Alonso de Cáceres, encomendero de Pocsi, cerca de Arequipa, que restituye a los indios de su encomienda en 1562, a título póstumo, 200 ovejas de Castilla, para aliviar su conciencia, sin mencionar las conquistas en las que participó. Las cláusulas de la restitución son bastante estrictas. Las

55. “[...] rruego e pido por merced a las justicias de Su Magestad que por todo rrigor de derecho o via executiva me compelan a mi y a los dichos mis herederos y albaceas a cumplir e pagar lo susodicho, según y de la forma que está dicho e declarado, bien ansy como si lo que dicho es y fuere sentencia definitiva de juez competente, por mí consentida e pasada en cossa juzgada, en razón de lo qual rrenuncio qualesquiera leyes, fueros y derechos y hordenamientos que en mi fabbor e de los dichos mis herederos sean o ser puedan", Vargas Ugarte, "Archivo de la beneficencia del Cuzco", 108.

56. Hampe Martinez, "Fray Domingo de Santo Tomás”, 355. 
ovejas no se pueden vender antes de que cuenten con 2000 hembras y su administración se atribuye al heredero del encomendero y al prior del convento de franciscanos de Arequipa, quienes son nombrados patrones de la obra pía, cuyo objetivo es financiar la caridad para los indios, ayudarlos a pagar el tributo y permitirle al franciscano que los evangeliza que complete sus ingresos. ${ }^{57}$ Como los hospitales fundados por Ribera, la mediación de los religiosos es también la regla en esta restitución condicional. Las fundaciones piadosas son típicas del comportamiento nobiliario, del deber de estado, que aquí se adapta al contexto andino. En este contexto, lo que notamos es que la guerra cede el paso como principio legitimador del estatus social, mientras que los antiguos conquistadores buscan una forma pacificada de legitimidad. Si bien la alusión al combate por la fe está presente en el caso de Nicolás de Ribera, ya no aparece con la restitución de Alonso de Cáceres, quien no se refiere a su papel como conquistador, ósea a una legitimidad fundada en su actuación militar contra supuestos infieles, que sabemos que tuvo en Santa Marta. Más bien hace hincapié en su papel de señor cristiano fiel servidor del Rey, quien vela por el bienestar material y la salvación espiritual de sus vasallos, así como financia las actividades de los religiosos en los Andes. ${ }^{58}$

La operación que consiste en restituirle bienes a los indios se transforma en acción piadosa, a través de la cual los encomenderos consiguen varios objetivos complementarios que van más allá de la cuestión moral. En primer lugar, al saldar su deuda se forjan un lugar legitimo en la sociedad colonial, a través de la categoría de devoto católico. Al mismo tiempo, la restitución elabora de manera duradera, la categoría del indio pobre y miserable, ya sea material como espiritualmente. La categoría del indio miserable fue también teorizada por Las Casas, remite a la debilidad jurídica de la población indígena y justifica la creación de la función de protector, que asumieron los religiosos en un primer periodo. ${ }^{59}$ Además,

57. Testamento de Alonso de Cáceres, Biblioteca Nacional del Perú, Manuscritos Z1264.

58. Lo mismo vemos con las restituciones de Gómez de Solis y Lorenzo de Aldana, estudiadas por Del Rio, María de las Mercedes del Rio, "Riquezas y poder: las restituciones a los indios del repartimiento de Paria", in Saberes y Memorias en los Andes. In memoriam Thierry Saignes, ed. Thérèse Bouysse-Cassagne (Paris: IHEALIFEA, 1997), 261-278.

59. Caroline Cunill, "El indio miserable: nacimiento de la teoría legal en la América colonial del siglo XVI," Cuadernos intercambio, 8, n9 (2011), 229-248. Caroline Cunill, Los defensores de indios en el Yucatán y el acceso de los mayas a la justicia colonial, 1540-1600 (Mérida: Universidad Nacional Autónoma de México, 2012). Carlos Sempat Assadourian, "Fray Bartolomé de las Casas obispo: la condición miserable de las 
a través de la restitución, Las Casas y los dominicos construyen la categoría del indio desposeído, a quién se le restablece en sus derechos con la justicia conmutativa que representa el acto de restituir.

Pero al mismo tiempo, al vestir la restitución con el hábito de la caridad, ésta se transforma en el don de un bien material, cuyo valor se puede evaluar y que sirve también para evangelizar a los indios. Con ese bien, el que restituye deposita un "tesoro en el cielo", según los términos de Peter Brown..$^{60}$ El testador/donador ejerce la caridad material y espiritual con sus obras pías y participa en la evangelización, que es su deber. Esta operación transforma entonces a los indios en sus deudores espirituales, con una deuda casi imposible de pagar, pues se trata de un bien, la salvación, cuyo precio no se puede evaluar. Las ovejas, un bien inmanente, se transforman a través de la obra pía en un bien transcendente, la salvación. ${ }^{61}$ La forma de la restitución tiene además una serie de consecuencias que refuerzan la relación de dominación entre encomenderos y comunidades indígenas. Restituir ovejas de Castilla, jamás robadas, pues no existían en los Andes, fue sin duda una de las maneras de imponer este ganado frente a las llamas tradicionales andinas y de ejercer un imperialismo ecológico que se manifiesta de muchas otras maneras. ${ }^{62}$ Ayudar a pagar el tributo apunta a mantener a la población indígena en las comunidades y evitar la migración. Se trata aquí muchas veces también de imponer la instalación de obrajes para el trabajo textil, una de las formas típicas de explotación de la mano de obra indígena en los Andes. ${ }^{63}$ Restituir con censos, bienes

naciones indianas y el derecho de la Iglesia (un escrito de 1545)," Allpanchis, XII, no. 35/36 (1990), 29-104; Carmen Ruigómez Gómez, Una política indigenista de los Habsburgo: el protector de indios en el Perú (Madrid: Cultura Hispánica, 1988).

60. Peter Brown, Treasure in heaven: the holy poor in early Christianity (Charlottesville: University of Virginia Press, 2016).

61. Sobre el ejemplo de Pocsi, un análisis más preciso en Aliocha Maldavsky, "Encomenderos, indios y religiosos en la región de Arequipa (siglo XVI): restitución y formación de un territorio cristiano y señoril," in Invertir en lo sagrado: salvación y dominación territorial en América y Europa (siglos XVI-XX), ed. Roberto Di Stefano y Aliocha Maldavsky (Santa Rosa: EdUNLPam, 2018): http://www.unlpam.edu.ar/cultura-y-extension/ edunlpam/catalogo/actas-de-eventos-academicos/invertir-en-lo-sagrado

62. Alfred W. Crosby, Ecological imperialism: the biological expansion of Europe, 900-1900 (Cambridge: Cambridge University Press, 2004). Alfred W. Crosby, The Columbian exchange: biological and cultural consequences of 1492 (Westport (Conn.)-Londres: Praeger, 2003). Elinor G. K. Melville, A plague of sheep: environmental consequences of the conquest of Mexico (Cambridge: Cambridge University Press, 1994).

63. Fernando Silva Santisteban, Los obrajes en el virreinato del Perú (Lima: Museo Nacional de Historia, 1964). 
y dinero pagados en un amplio lapso de tiempo, varios años después de la muerte del testador, son también mecanismos que permiten reforzar los lazos de dominación y buscan ampliar la duración de la dependencia entre el encomendero y las comunidades indígenas. A lo mismo apunta el nombramiento de patrones laicos o religiosos.

Los documentos sobre la práctica de la restitución nos muestran que los españoles adaptaron sus representaciones fundadas en el ideal de la Reconquista a la nueva configuración de la sociedad colonial, cuya jerarquía se define también con criterios religiosos, pero donde la caridad tiende a remplazar a la guerra. La restitución permite construir una dualidad entre el encomendero señor de indios y los indios, eternos neófitos. ${ }^{64}$ En los textos de restitución, las autoridades tradicionales, curacas y caciques, aparecen muy poco. Su estatus es ambiguo, pues son indios y al mismo tiempo se les reconoce un lugar elevado en la jerarquía, por lo tanto, adoptan comportamientos socio-religiosos aristocráticos conformes a los que buscan los encomenderos.

\section{Conclusión}

La obligación de restituir los bienes a los indios, enunciada por los religiosos con Bartolomé de Las Casas, se refiere en primer lugar al sacramento de penitencia, desde el punto de vista de la teología moral. En el ámbito político, la restitución cuestiona el derecho de conquista y la soberanía española en América, pero también acata los hechos y busca un compromiso colonial ya que no se puede volver atrás. Este compromiso depende de la reparación de los daños cometidos contra los indios y de su conversión al catolicismo en una sociedad cristiana. Luego del fracaso de las Leyes Nuevas, que no lograron poner fin a la institución de la encomienda, los religiosos utilizan la teología moral para intervenir en cada conciencia individual y la restitución, impuesta a los antiguos conquistadores, funciona como un "encaje penitencial", que a punta restablecer la justicia gracias al foro de la conciencia. Con la restitución los religiosos contribuyen a reforzar la categoría del indio jurídicamente miserable, víctima del robo y de la guerra injusta, del que se reivindican como defensores. En la práctica, no se trata de eliminar a los encomenderos de la

64. Juan Carlos Estenssoro Fuchs, Del paganismo a la santidad: la incorporación de los Indios del Perú al catolicismo, 1532-1750 (Lima: IFEA, 2003). 
sociedad, sino de definir su lugar en un contexto ya pacificado, de otorgarles un estatus del que se pueden apoderar de forma activa.

Es lo que sucede con las restituciones concretas que se pueden estudiar con los documentos notariales. Las obras pías, donaciones y legados para hospitales de indios o los dones de ovejas para la caridad y el tributo, no solamente le atribuyen un lugar a cada uno en la sociedad colonial, sino además refuerzan la jerarquía en la que los encomenderos aspiran a ocupar el primer lugar. El argumento de la buena fe les permite transformar la restitución de bienes a los indios en un don caritativo, típico de los deberes del estado de noble, y de aparecer además como devotos cristianos fieles a su Rey, sin olvidar su papel de guerreros. En esta operación, los indios pasan de un estatuto de infieles al de neófitos, miserables ya sea desde el punto de vista de la justicia como de la fe. Entre los dos, los religiosos tienen un papel de mediadores que los documentos notariales permiten fundamentar.

\section{Referencias}

Adorno, Rolena. Polemics of Possession in Spanish American Narrative. New Haven: Yale University Press, 2007.

Brown, Peter. Treasure in heaven: the holy poor in early Christianity. Charlottesville: University of Virginia Press, 2016.

Las Casas, Bartolomé de. Aqui se contienen unos avisos y reglas para los que oyeren confessiones de los Españoles que son o han sido en cargo a los indios de las Indias del mas Océano. Sevilla: Sebastián Trujillo, 1552 [Obras escogidas, t. V, Opusculos, cartas y memoriales (Madrid: Biblioteca de Autores Españoles, 1958), 235-249].

Abercrombie, Thomas. "Tributes to Bad Conscience: Charity, Restitution, and Inheritance in Cacique and Encomendero Testaments of 16th-Century Charcas." In Dead Giveaways, Indigenous Testaments of Colonial Mesoamerica end the Andes, edited by Susan Kellogg and Matthew Restall, 249-289. Salt Lake city: University of Utah Press, 1998.

Azpilcueta Navarro, Martin de. Manual de penitentes. Estella: Adrián de Anvers, 1566.

Benito, José Antonio. La Bula de Cruzada en Indias. Madrid: Fundación Universitaria Española, 2000.

Boer, Wietse de. La conquista dell'anima. Turin: Einaudi, 2004.

Cantú, Francesca, "Evoluzione et significato della dottrina della restituzione in Bartolomé de Las Casas. Con il contributo di un documento inedito." Critica Storica, XII-Nuova serie, n²-3-4 (1975), 231-319.

Crosby, Alfred W. Ecological imperialism: the biological expansion of Europe, 900-1900. Cambridge: Cambridge University Press, 2004.

Crosby, Alfred W. The Columbian exchange: biological and cultural consequences of 1492. Westport (Conn.)-Londres: Praeger, 2003.

Cunill, Caroline. "El indio miserable: nacimiento de la teoría legal en la América colonial del siglo XVI." Cuadernos intercambio 8, no.9 (2011), 229-248.

Cunill, Caroline. Los defensores de indios en el Yucatán y el acceso de los mayas a la justicia colonial, 
1540-1600. Mérida: Universidad Nacional Autónoma de México, 2012.

Del Rio, Maria de las Mercedes. "Riquezas y poder: las restituciones a los indios del repartimiento de Paria." In Saberes y Memorias en los Andes. In memoriam Thierry Saignes, edited by Thérèse Bouysse-Cassagne, 261-278. Paris : IHEAL-IFEA, 1997.

Dictionnaire de théologie catholique. Paris : Letouzey et Ané, 1937.

Egaña, Antonio de. Monumenta Peruana 3. Rome: Institutum Historicum Societatis Iesu 1954.

Estenssoro Fuchs, Juan Carlos. Del paganismo a la santidad: la incorporación de los Indios del Perú al catolicismo, 1532-1750. Lima: IFEA, 2003.

Hampe Martinez, Teodoro, "Fray Domingo de Santo Tomás y la encomienda en el Perú (15401570)." Los dominicos en el Nuevo mundo, edited by José Barrado, 355-379. Salamanca: San Esteban, 1990.

Hanke, Lewis. La Lucha por la justicia en la conquista de América. Buenos Aires: Ed. Sudamericana, 1949.

Konetzke, Richard. Colección de documentos para la Historia de la Formación social de Hispanoamérica, 1493-1810. T.I. Madrid: CSIC, 1953.

Las Casas, Bartolomé de. Del único modo de atraer a todos los pueblos a la verdadera religión. Edited by Lewis Hanke, México: Fondo de cultura económica, 1975 [1942].

Lavenia, Vincenzo. "L'Église, juge du fisc : théologie et impôt aux XVIe et XVIIe siècles." In Philosophie de l'impôt, edited by Thomas Berns, Jean-Claude K. Dupont, Mikhail Xifaras, 37-67. Bruxelles : Bruylant, 2006.

Lavenia, Vincenzo, L'infamia e il perdono: tributi, pene e confessione nella teologia morale della prima età moderna. Bologne: Il Mulino, 2004.

Lisson Chaves, Emilio. La Iglesia de España en el Perú. Savilla: Editorial católica española, 1944.

Lohmann Villena, Guillermo. "El encomendero indiano, cooperador de la evangelización." In Homenaje al profesor Alfonso García Gallo, vol. 5, 113-136. Madrid: Universidad Complutense, 1996.

Lohmann Villena, Guillermo. "La restitución por conquistadores y encomenderos: un aspecto de la incidencia lascasiana en el Perú.” Anuario de Estudios americanos 23 (1966), 21-89.

Maldavsky, Aliocha. "Encomenderos, indios y religiosos en la región de Arequipa (siglo XVI): restitución y formación de un territorio cristiano y señoril", in Invertir en lo sagrado: salvación y dominación territorial en América y Europa (siglos XVI-XX), edited by Roberto Di Stefano and Aliocha Maldavsky. Santa Rosa: EdUNLPam, 2018. http://www.unlpam. edu.ar/cultura-y-extension/edunlpam/catalogo/actas-de-eventos-academicos/invertir-en-losagrado.

Melville, Elinor G. K. A plague of sheep: environmental consequences of the conquest of Mexico. Cambridge: Cambridge University Press, 1994.

Pagden, Anthony. "The school of Salamanca and the 'Ius Naturae'." In The uncertainties of empire: essays in Iberian and Ibero-American intellectual history. Aldershot: Variorum, III.

Pagden, Anthony. "Dispossessing the barbarian: the language of Spanish Thomism and the debate over the property rights of the American Indians." In The languages of political theory in early modern Europe, edited by Anthony Pagden, Anthony, 79-98. Cambridge: Cambridge University Press, 1987.

Prodi, Paolo. Una historia de la justicia. De la pluralidad de fueros al dualismo moderno entre conciencia y derecho. Buenos Aires-Madrid: Katz, 2008.

Recopilación de las leyes de Indias. Madrid: Julián de Paredes, 1681.

Río, María de las Mercedes del. Etnicidad, territorialidad y colonialismo en los Andes: tradición y cambio entre los Soras de los siglos XVI y XVII, Bolivia. Lima: Instituto Francés de Estudios Andinos, 2005.

Riva-Agüero, José de la. El primer alcalde de Lima, Nicolas de Ribera el viejo y su posteridad. Lima: Librería e imprenta Gil, 1935.

Ruigómez Gómez, Carmen. Una política indigenista de los Habsburgo: el protector de indios en el 
Perú. Madrid : Cultura Hispánica, 1988.

Salinero, Gregorio. La trahison de Cortés : désobéissance, procès politiques et gouvernement des Indes de Castilles, seconde moitié du XVIe siècle. Paris: Presses universitaires de France, 2014.

San Martin, Tomás de. "Parecer de D. Fr. Tomas de San Martin, obispo de Charcas, sobre si son bien ganados los bienes adquiridos por los conquistadores, pobladores y encomenderos de las Indias." Colección de documentos inéditos relativos al descubrimiento, conquista y organización de las antiguas posesiones españolas de América y Oceanía, vol. 7, 348-362. Madrid: Frias y Cia., 1867.

Sempat Assadourian, Carlos. "La renta de la encomienda en la década de 1550: piedad cristiana y deconstrucción.” Revista de Indias vol. XLVIII, no. 182-183 (1988), 109-146.

Sempat Assadourian, Carlos. "Fray Bartolomé de las Casas obispo: la condición miserable de las naciones indianas y el derecho de la Iglesia (un escrito de 1545)." Allpanchis, XII, no. 35/36 (1990), 29-104.

Silva Santisteban, Fernando. Los obrajes en el virreinato del Perú. Lima: Museo Nacional de Historia, 1964.

Tibesar, Antonine. "Instructions for the Confessors of Conquistadores Issued by the Archbishop of Lima in 1560." The Americas 3, no. 4 (Apr. 1947) 519-534.

Trelles Aréstegui, Efraín. Lucas Martínez Vegazo: funcionamiento de una encomienda peruana inicial. Lima: Fondo editorial de la Pontificia universidad católica del Perú, 1991.

Vargas Ugarte, Rubén. "Archivo de la beneficencia del Cuzco." Revista del Archivo Histórico del Cuzco, $\mathrm{Cuzco}^{\circ} 4$ (1953)105-106.

Zavala, Silvio. El servicio personal de los indios en el Perú, 3 vol. México: El Colegio de México, 1978.

Zavala, Silvio. La encomienda indiana. Madrid: Junta para ampliación de estudios e investigaciones científicas-Centro de estudios históricos, 1935. 